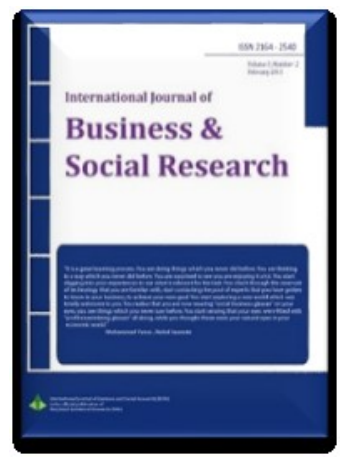

\title{
Assessment of the Effects of the Free Maternal Health Policy on Maternal Health: A Case Study of New Juaben Municipality, Koforidua, Ghana.
}

\author{
Nicholas Apreh Siaw 1 , Samuel Kwofie ${ }^{2}$
}

\begin{abstract}
The main objective of the study was to verify the effect of the free maternal care policy on maternal health in the New Juaben Municipality, Ghana. The population for the study encompassed women of the child bearing age (10-49) in the New Juaben Municipality. Both primary and secondary sources of data were employed for this study. Purposive and accidental sampling procedures were used to select the respondents. The sample size was two hundred (200). This study used trend analysis as its main approach of analyzing the available data. The findings show that antenatal attendance has been increasing over the years. This is attributed to the introduction of the free maternal health policy. However, quality of care remains a problem due to the enormous attendance. It was also recommended that there is still a great need to introduce other measures to reduce maternal mortality in the municipality. It was also recommended that quality of care must be addressed and also more efforts should be made in the services that have provided to the patients. It was concluded that, although the policy has not eradicated maternal mortality completely yet it has contributed to its significant reduction in the region.
\end{abstract}

Keywords: Mental health; Non-parametric study; Ghana.

Available Online: 14-08-2016

This is an open access article under Creative Commons Attribution 4.0 License, 2016.

\section{INTRODUCTION}

\subsection{BACKGROUND TO THE STUDY}

At the turn of this century, 189 countries endorsed the Millennium Declaration and signed up to meeting eight goals. One of these (Millennium Development Goal 5) is to "improve maternal health" (Lancet, 2005). The concept of maternal mortality has become an everyday phenomenon of the contemporary world. Women of childbearing age all over the world irrespective of race, education, occupation or marital status are faced with the agony of pregnancy's related challenges leading to their

\footnotetext{
${ }^{1}$ Applied Mathematics Department, Koforidua Polytechnic, School of Applied Science and Technology. Email: rockstahus@yahoo.com
}

2.Applied Mathematics Department, Koforidua Polytechnic, School of Applied Science and Technology. Email: rockstahus@yahoo.com 
dead. The concentration before this era was argued on the ability to bear children and thus people though sad, were happy for the children's' survival. Global attention, however, began to focus more seriously on maternal deaths in the 1980's precisely 1985 when, Rosenfield and Maine published a thought-provoking article in the Lancet (Senah, 2003). In the article titled 'Maternal Mortality-a neglected tragedy-where is the $\mathrm{M}$ in $\mathrm{MCH}$ ?' Rosenfield and Maine warned the world of the fact that many countries were neglecting this important problem and that existing programs were unlikely to reduce the high maternal mortality rates (Senah, 2003). Hence, in 2008, the Government of Ghana, introduced the free maternal policy which aimed at tackling this minas.

\subsection{STATEMENT OF THE PROBLEM}

The Eastern Regional Hospital in Koforidua recorded a total of 41 maternal deaths in 2010, as against 36 recorded in 2009. According to Dr Anim Boamah, head of the Department of Obstetrics and Gynaecology of the Regional Hospital, the high rate of maternal deaths is attributable to high abortion related deaths, primary post partum haemorrhage, hypertensive diseases in pregnancy and ruptured uterus, HIV related deaths and pre-natal infections. The others included placental abruption, cardiac failure and Sickle cell disease with anaesthetic death, ectopic pregnancy, pulmonary embolism, obstructed labour and hypoglycaemia recording death each. (GNA, 2010). Reasons attributed to these deaths were late referrals (adding that documents of most of those referrals were either incomplete or had some vital information on them being omitted). Dr. Anim Boamah indicated that 2010 had 27 out of 37 maternal mortality cases resulting from late referrals. Five (5) of these pregnant women were already brought in dead. However in 2003, to improve maternal health and survival, the government of Ghana implemented a new policy that removed delivery fees in Health facilities in the four mostdeprived regions of the country. Less than two years later, the government extended the policy to the rest of Ghana, removing delivery fees in all public, private and mission facilities (Impact, PRB, 2007). On July 1st, 2008 the President of Ghana announced that the government is providing free maternal care for pregnant women to improve the attainment of MDG 4 and 5. The decision was to implement this through NHIS (National Health Insurance scheme) to give all mothers full package access to antenatal, prenatal and postnatal care (NHIS, 2008). As a result of the high rate of maternal mortality recorded in the district, it was necessary to undertake research in other to carefully access the major causes of maternal mortality at the expense of free maternal health care.

\subsection{OBJECTIVES OF THE STUDY}

The main objective of the study is to assess the effect of the free maternal health policy on utilization of maternal health services in the New Juaben Municipality.

More specifically the study aimed to;

I. Assess the trend in the antenatal attendance in the health care facilities after the implementation of the free maternal health care policy.

II. Analyze the effect of the policy on the quality of care in the health facilities.

III. Examine the prospects and challenges of the policy and make recommendations to the problem.

\subsection{METHODOLOGY}

\subsection{PROFILE OF THE NEW JUABEN MUNICIPALITY}

\subsubsection{LOCATION}

The New Juaben is the regional capital of the Eastern Region and has an estimated population of 152,858. It covers a land size of 110.0 square kilometers with a population density of 1,483 . The Municipality shares boundary on the North with East Akim District, on the South with Akwapim North, 
Yilo Krobo on the East and Suhum Kraboa Coaltar on the West. It lies between latitude 60 degrees North and 70 degrees North (New Juaben Municipal Health Directorate, 2012).

\subsubsection{HEALTH FACILITIES}

The inhabitants seek health services through the following network of health facilities;

\begin{tabular}{lr}
\hline \multicolumn{2}{c}{ Table 3.1: Type of Facilities } \\
\hline Type of Facility & Quantity \\
\hline Regional Hospital & 1 \\
Mission Hospital & 1 \\
Health Centres & 2 \\
Private Clinics & 11 \\
Private Maternity Homes & 3 \\
RCH Centres & 10 \\
Trained Traditional Birth Attendants (TBAs) & 80 \\
CHHPS Centres & 5 \\
Pharmacy/ Chemical Shops & 70 \\
Total & 204 \\
\hline Source: New Juaben Municipal Directorate-Disease and Preventive Unit-2012 &
\end{tabular}

\subsection{TARGET POPULATION AND SAMPLING TECHNIQUES}

The population for the study encompasses women of child bearing age (10-49) in the New Juaben Municipality as prescribed by the New Juaben Municipal Health Directorate. Pregnant women who are using and have ever used the free maternal health care was chosen for this study because they are viewed to be much more informed of the pros and cons of the policy and can throw more light on the interview. The Municipality Health Directorate has divided the municipality into sub-municipalities comprising Oyoko/Jumapo, Effiduase/Asokore/Akwadum, Koforidua/Zongo, Regional Hospital, Medical Village, Private Maternity, Traditional Birth Attendants and SDA Hospital. Secondary data from all these facilities were used in the analysis.

However out of these health facilities, five (5) health facilities that admit and deliver pregnant women were chosen as the target health facilities from which respondents were picked for the primary data. They are the Eastern Regional Hospital, Zongo Health Centre, Akwadum RCH, Jumapo Health Centre and Pat Maternity Home. The study requires a focus on a targeted sample of women in the New Juaben municipality who have used and are using the free maternal health services in the last five years. Two sampling techniques namely the purposive sampling and accidental sampling techniques were employed to select respondents to participate in the study.

After purposively selecting those beneficiaries who have used these services in the stated years, the accidental sampling technique was used to gather information from three hundred (300) women who are using the free maternal health policy from the five selected facilities that admit and deliver pregnant women in the New Juaben municipality.

Three hundred (200) questionnaires were administered. Out of this, one hundred (100) respondents were selected from the Regional Hospital, twenty-five (25) from Zongo Health Centre, twenty-five (25) from Akwadum RCH, twenty-five (25) from Jumapo Health Centre and twenty-five (25) from Pat Maternity Home. The assigning of this quota of respondents to these health facilities is in response to the number of attendance to these facilities.

\subsection{DATA COLLECTION PROCEDURE}


The researcher carried out a pre-test on the primary data to authenticate the validity and reliability of his interview guide before the start of his actual field work. A total of ten (10) questionnaires and two (2) interviews were carried out during the period of the pre-test. The questionnaires were then restructured and the necessary corrections made before the actual fieldwork was carried out. To avoid false information during the actual field study women used for the pre-test were different from those used for the actual study.

\section{$2.4 \quad$ RESEARCH DESIGN}

A secondary data (quantitative) supported by a structured interview (qualitative) were used as the main instruments to gather the data from the women from the five health facilities. The first section of the interview for the women solicited information on the background beneficiaries. They constituted questions about age, education, marital status, occupation while the questions in the second section tackled their utilization and accessibility of the health care services and challenges faced. The research design chosen for this work was the descriptive survey design. This study also used trend analysis as its main approach of analyzing the available data.

Both primary and secondary sources of data were employed for this study. The secondary data consulted includes annual reports, presentations at key conferences, annual statistics, half year reports, policy documents, books and other documents about maternal care in the New Juaben Municipality. To buttress points on the free maternal care and utilization rate and to complement the field data. It also gave direction to the study by providing the researcher with fair knowledge about the impact of the free maternal care policy on maternal care services.

The primary data, on the other hand, were obtained from respondents in New Juaben Municipality through interviews with the help of a semi-structured interview guide. The use of this technique gave the researcher the chance to appraise the validity and reliability of the respondents' answers. It also gives the investigator access to vital information which the secondary data could not provide.

\subsection{DATA ANALYSIS}

The study also used the trend analysis as its source of the data analysis. This arose out of the type of study being carried out. Rosenberg (1997) states the selection of a strategy for analyzing trend data depends in part on the purpose of the analysis by the researcher. She indicates once there is a sound conceptual framework, tables, graphs and statistical analysis are tools for examining and analyzing trend data; graphs, in particular, are an effective tool for presenting the pattern of change over time.

Under trend analysis regardless of whether statistical techniques were used for analyzing data over time, the most straightforward and intuitive first step in assessing a trend is to plot the actual observed numbers or rates of interest by year (or some other period deemed appropriate

\subsection{DATA ANALYSIS AND DISCUSSION OF RESULTS}

\subsection{SOCIO-ECONOMIC BACKGROUND OF WOMEN RESPONDENTS}

\begin{tabular}{lrr}
\hline \multicolumn{2}{c}{ Table 4.1.1 } & \\
\hline Age & Frequency & Percentages (\%) \\
\hline $10-19$ & 40 & 20 \\
$20-29$ & 100 & 50 \\
$30-39$ & 40 & 20 \\
$40+$ & 20 & 10 \\
Total & 200 & 100 \\
\hline Field Data, 2013 & & \\
\hline
\end{tabular}


From the table 4.1.1, it is observed that a total number of two hundred (200) women were interviewed. It is observed that 20-29 age group have the highest representation of 50 percent. The $40+$ age group has the least representation of 10 percent. It is observed that most of the respondents are the youth between the ages of 20-29 years. This means that when a policy is going to be made, it should be focused on 20-29 age group because they have the highest percentage.

Table 4.1.2 Marital Status of Respondents

$\begin{array}{lrr}\text { Marital status } & \text { Frequency } & \text { Percentage } \\ \text { Married } & 60 & 30 \\ \text { Single } & 90 & 45 \\ \text { Separated } & 50 & 25 \\ \text { Total } & 200 & 100\end{array}$

Source: Field/primary data 2013.

Table 4.1.2 above throws light on the distribution of the respondents by marital status. It could be seen from Table 4.1.2 that out of two hundred (200) respondents, the majority of them, representing 45 percent were married and 30 percent were single. The least of 25 percent were separated. This means that those who are married enjoyed the services more than those who are not married.

\subsection{THE TREND IN THE ANTENATAL ATTENDANCE AFTER THE POLICY}

Table 4.2.1: Antenatal Coverage (2007-2012)

$\begin{array}{lrrr}\text { Period/Year } & \text { Antenatal Registrants } & \begin{array}{r}\text { Average No. of visit per } \\ \text { client }\end{array} & \begin{array}{r}\text { \% of antenatal mothers that } \\ \text { received care }\end{array} \\ 2007 & 4884 & 3.0 & 160.8 \\ 2008 & 5463 & 4.0 & 93.1 \\ 2009 & 5027 & 4.1 & 84.5 \\ 2010 & 5190 & 4.6 & 86.1 \\ 2011 & 5599 & 4.8 & 92.0 \\ 2012 & 5570 & 4.1 & 89.9\end{array}$

Source: New Juaben Municipal Health Directorate-Reproductive and Child Health

Registered antenatal totaled 4884 for the year 2007, and kept on increasing in the subsequent years up to 5570 in the year 2012. The total number of antenatal who registered their pregnancies has picked up over the years. Similarly, the average number of visits per client has improved over the past years, from 3.0 in 2007 to 4.1 in 2012.

Figure 1: Trend analysis plot for antenatal attendance

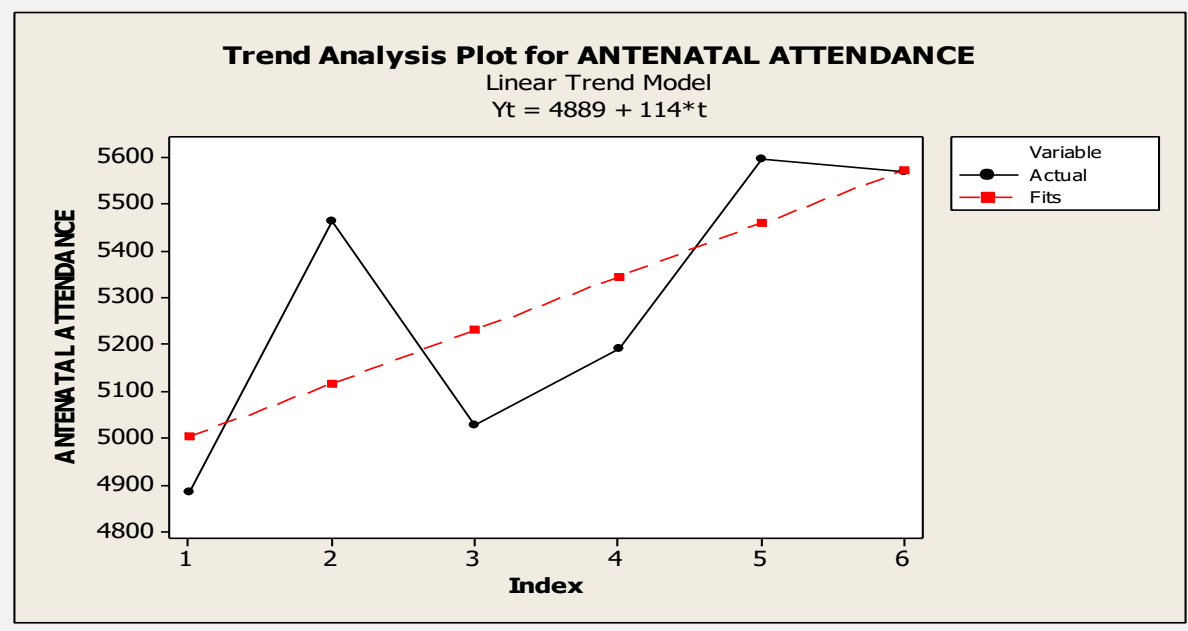


Over all, the proportion of antenatal that received care has also been increasing and decreasing since the year 2007 to 2012. However, the proportion of antenatal that received care has been hovering above 8 opercent which is encouraging.

From Figure 1, that is the Trend Analysis Plot for Antenatal Attendance, the index that is 1,2,3,4,5and 6 represents the years 2007, 2008, 2009, 2010, 2011 and 2012 respectively

\subsection{ASSESSMENT OF THE EFFECT OF THE POLICY ON THE QUALITY OF CARE IN THE HAELTH FACILITIES}

\begin{tabular}{lrr}
\hline \multicolumn{2}{c}{ Table 4.3.1: Overall performance of the free maternal care policy } \\
\hline Performance & Frequency & Percentage \\
\hline Excellent & 10 & 5 \\
Very good & 20 & 10 \\
Good & 40 & 20 \\
Satisfactory & 100 & 50 \\
Poor & 30 & 15 \\
Total & 200 & 100
\end{tabular}

Source: Field/ primary data 2013

Table 4.3.1 above indicates the responses on the overall performance of the free maternal care policy. From Table 4.3.1, 50 percent said that the overall performance of the free policy was satisfactory, followed by 2opercent who said the overall performance of the free policy was good, and 15 percent and 10 percent said the overall performance was poor and very good respectively. The least of 5 prcent said the overall performance of the free policy was excellent.

Figure 2: Overall performance of the free maternal care policy

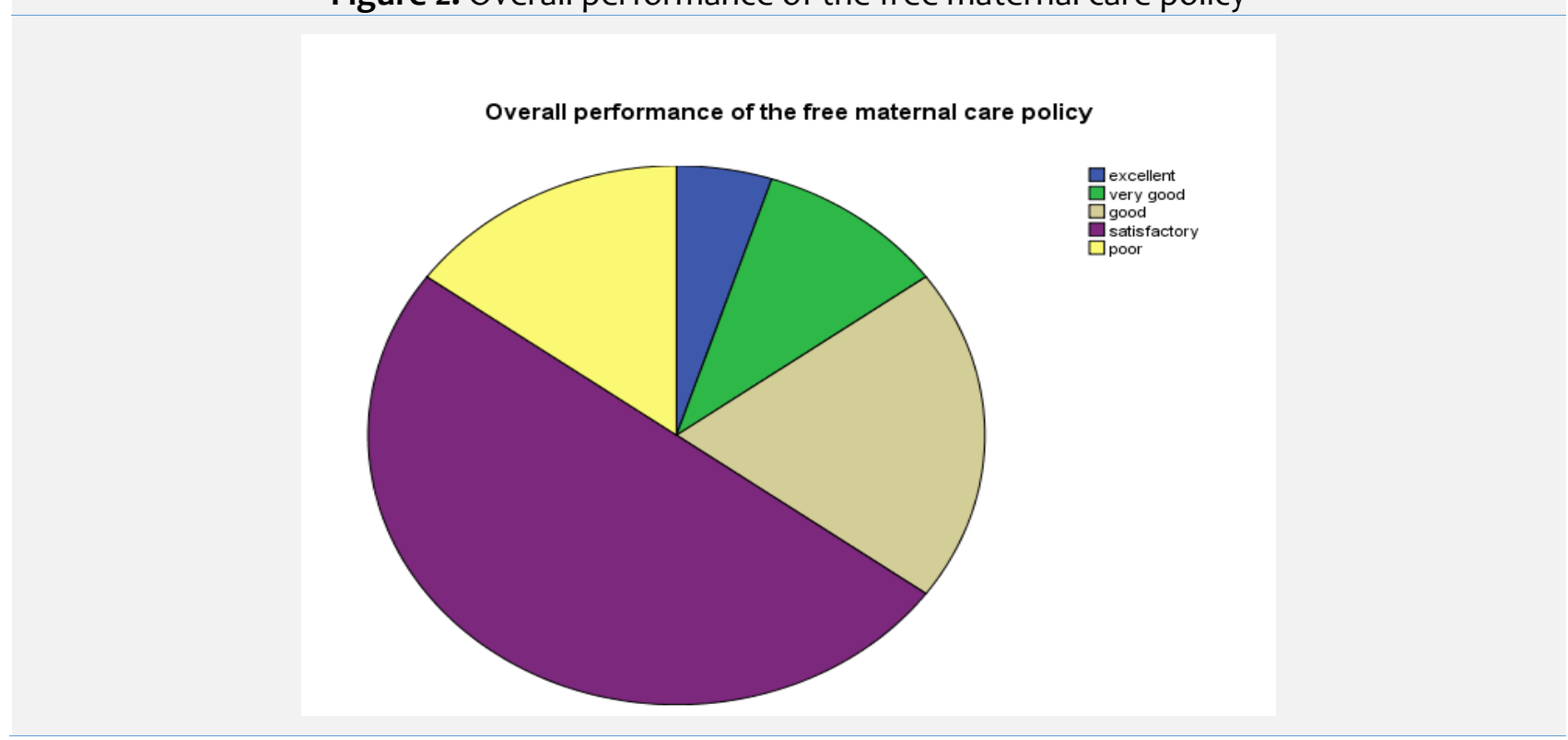

\begin{tabular}{lrr}
\hline \multicolumn{3}{|c|}{ Table 4.3.2: Attitude of health professionals at each service point } \\
\hline Attitude & Frequency & Percentage \\
\hline very good & 20 & 10.0 \\
good & 40 & 20.0 \\
satisfactory & 80 & 40.0
\end{tabular}




\begin{tabular}{lrr}
\hline not good & 60 & 30.0 \\
Total & 200 & 100.0 \\
\hline Source: Field/ primary data 2013 & & \\
\hline
\end{tabular}

Table 4.3.2 above indicates the responses on the attitude of health professionals at the service points. From Table 4.3.3, 40 percent indicated that the attitude of the health professional was satisfactory, followed by 30 percent who said the attitude of health professionals was not good, and 20 percent said the attitude of health professionals was good. The least of 10 percent said the attitude of health professionals was very good.

Figure 3: Attitude of health professionals at each service point

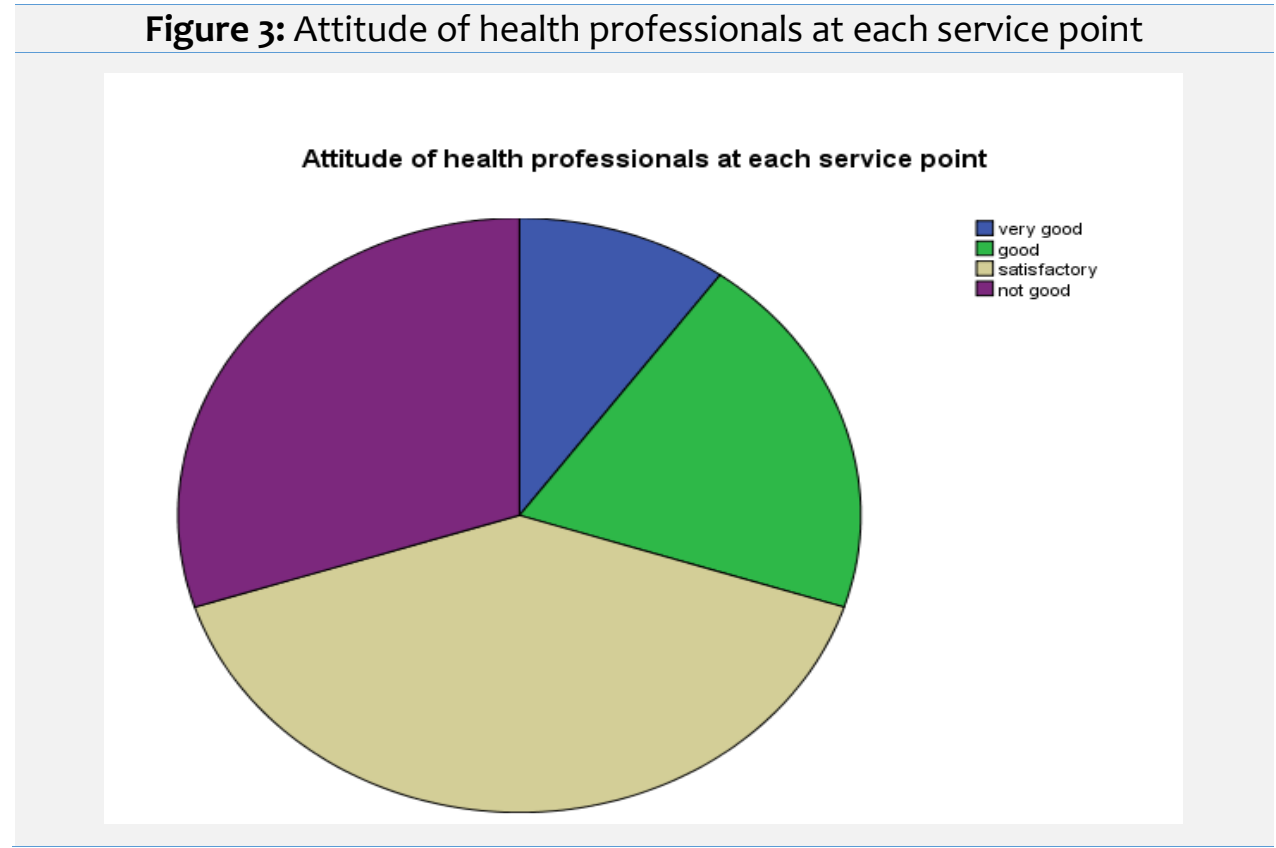

Satisfaction level

Table 4.3.4: Level of satisfaction with the service providers

Very satisfied

Frequency Percentage

Satisfied

$10 \quad 5$

Little satisfied

Dissatisfied

Total

200

Source: Field/ primary data 2013

Figure 5: Level of satisfaction with the service providers 
Table 4.3.4 above indicates the responses on the level of satisfaction with the service providers. From Table 4.3.4, 60 percent had little satisfaction with the service providers, followed by 25 percent being satisfied with the service providers, 10 percent been dissatisfied with the service providers and also 5 percent been very satisfied with the service providers. More effort should be made in the services being provided to the patients.

\subsection{THE PROSPECTS AND CHALLENGES OF THE POLICY}

\begin{tabular}{lrr}
\hline \multicolumn{2}{c}{ Table 4.4.1: The challenges with the policy } & \\
\hline Challenges & Frequency & Percentage \\
\hline Delay at service point & 70 & 35 \\
Patients with NHIS are not treated well & 70 & 35 \\
Card acquisition problem & 20 & 10 \\
Drugs are not of good quality & 40 & 20 \\
Total & 200 & 100 \\
\hline Source: Field/ primary data 2013 & &
\end{tabular}

Table 4.4.1 above indicates the responses to the challenges with the policy. From Table 4.4.1, 35 percent said the challenge with the policy is the delay at the service points and patients with NHIS are not treated well, followed by 20 percent said the drugs were not of good quality, and the least of 10 percent said the challenge is with the card acquisition.

Table 4.4.2: Recommended solutions

$\begin{array}{lrr}\text { Recommendation } & \text { Frequency } & \text { Percentage } \\ \text { Time spent at the facility should be reduced } & 70 & 35 \\ \text { Patients with NHIS should be treated well } & 70 & 35 \\ \begin{array}{l}\text { Bottlenecks with card production and distribution } \\ \text { should be cleared }\end{array} & 20 & 10 \\ \text { More quality drugs should be added } & 40 & 20 \\ \text { Total } & 200 & 100 \\ \text { Source: Field/ primary data } 2013 & & \end{array}$

Table 4.4.2 above indicates the responses on the recommended solutions to the challenges with the policy. From Table 4.4.2, 35 percent said the time spent at the facility should be reduced, and patients with NHIS should be treated well, followed by 20 percent who said more quality drugs should be added. The least of 10 percent said the bottlenecks with the card production and distribution should be removed.

Figure 7: Recommended solutions

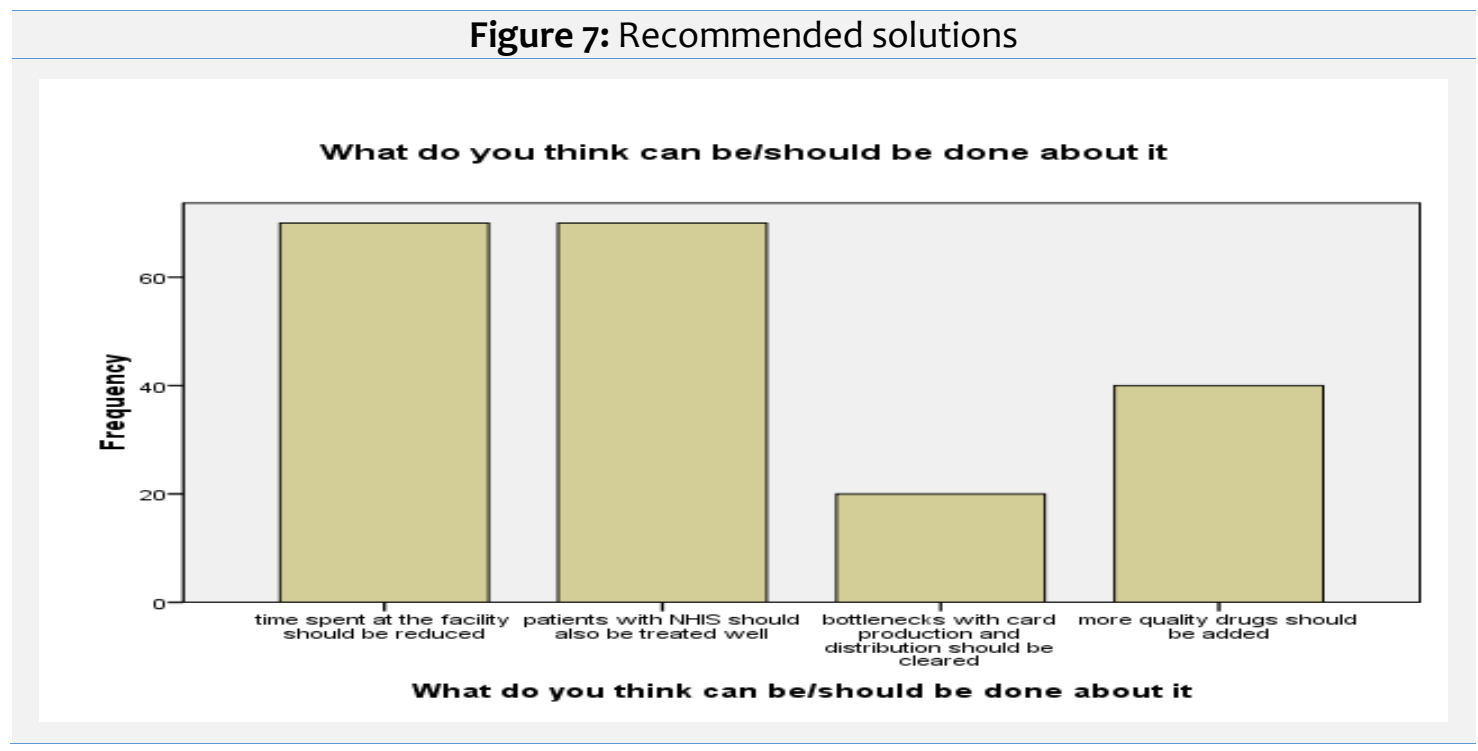


Table 4.4.3 above indicates the responses on the reason to maintain the policy. From Table 4.4.3, 54 percent said the policy should be maintained because it helps those who cannot afford health care to access health care and 46 percent who said the policy should be maintained because it encourages pregnant women to go for regular treatment.

Figure 8: Why should the free maternal policy be maintained

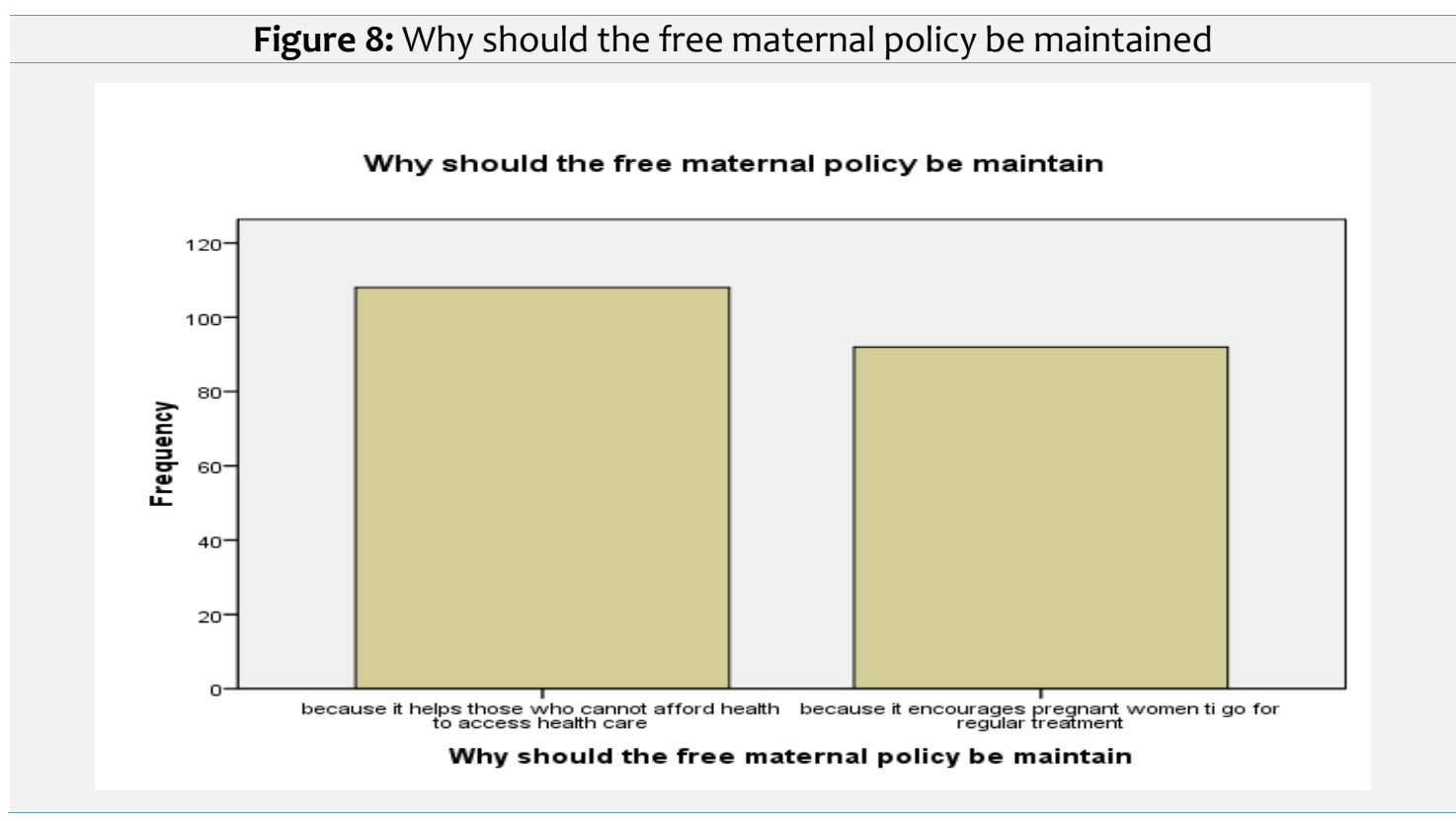

\subsubsection{ANTENATAL ATTENDANCE IN THE HEALTH CARE FACILITY AFTER THE IMPLEMENTATION OF THE FREE MATERNAL HEALTH CARE POLICY}

Ghana Health insurance (under which the free maternal care policy falls) allows (6) ANC visits (NHIS, 2010). As shown in Table 4.2.1, registered antenatal totaled 4884 for the year 2007, and kept on increasing in the subsequent years up to 5570 in the year 2012. The total number of antenatal out of the expected pregnancies, who registered their pregnancies, has been increasing over the years. Similarly, the average number of visits per client has also improved over the past years, from 3.0 in 2007 to 4.1 in 2012. This antenatal increases in the municipality can be attributed to the coming into being of the free maternal healthcare policy.

\subsubsection{THE EFFECT OF THE POLICY ON THE QUALITY OF CARE IN THE HEALTH FACILITY}

The presence and quality of care imparted by the health service providers, availability of equipment and medical supplies in the health service facility determines the decision of the needy women to visit the facility (United Nations Economic and Social Commission for Asia and the Pacific, 2008). Some mortality cases in the municipality arises out of shortage of blood/ non availability of fresh frozen plasma, lack of adequate intravenous fluids and other supplies, (NJMHD, 2009).

From table 4.3.1 shows that 5opercent said the overall performance of the free policy was satisfactory, followed by zopercent who said the overall performance of the free policy was good and 15percent and 10percent said the overall performance was poor and very good respectively. The least of 5 percent said the overall performance of the free policy was excellent. The implication is that close 4opercent said the attitude of the health professional was satisfactory, followed by 3opercent who said attitude of health professionals was not good and 2opercent said attitude of health professionals was good. The least of 1opercent said attitude of health professionals was very good.

From table 4.3.3, 6opercent said the effectiveness of the NHIS medicine given was satisfactory, followed by zopercent and 15percent said the medicine were very good and good respectively and the least of 5 percent said the medicine was not good. 
From table 4.3.4, 6opercent had little satisfaction with the service providers, followed by 25 percent been satisfied with the service providers, 10percent been dissatisfied with the service providers and also 5 percent been very satisfied with the service providers.

Hence the overall findings can be summarized as:

- The study showed that the registered antenatal totaled 4884 for the year 2007 kept on increasing in the subsequent years up to 5570 in the year 2012.

- Also, it was observed that only 10 percent of the attitude of the health professionals was very good.

- Further, 60 percent of the respondents are satisfied with the NHIS medicine to give to them and also 60 percent had little satisfaction with the service providers.

- The study revealed that the challenge of the policy was the delay at the service point, and also patients with NHIS are not treated well.

\subsection{RECOMMEDATIONS}

The issue of Maternal Mortality in Ghana is of concern and will continue to be of concern if certain parts of the problem are not addressed well. Ghana needs to focus on several key areas to help reduce maternal mortality. The ultimate goal for MDG 5 is to reduce maternal mortality by three quarters by the year 2015. The country will be able to make some strong reductions in specific areas of trouble they are currently facing with the high rate of maternal if other strategies apart from free healthcare are employed. Ghana is heading in the right direction with their sense of urgency to come up with solutions to the problem and the willingness to draw from various expertise. The study, therefore, makes these recommendations;

- Since the registered antenatal has kept on increasing in the subsequent years, the government should add new things to the existing policy so that many pregnant women will register for their antenatal.

- Management should train service providers to improve the quality of care.

- Since only 10 percent of the respondents said the attitude of the professionals was very good, management should organize workshops for the health professionals to work on their attitude.

- Time spent at the service point should be reduced and also patient with NHIS should be treated with care like the way patients without NHIS are treaded.

\subsection{CONCLUSION}

Based on the problem posed by maternal mortality and its effect on achieving the target set by the Millennium Development Goals, the following objectives which have been elaborated below were formulated for the investigation:

Firstly, the research aimed at establishing the trends in the antenatal attendance in the health care facilities after the implementation of the free maternal health care policy. The total number of antenatal out of the expected pregnancies, who registered their pregnancies, has been increasing over the years. Similarly, the average number of visits per client has also improved over the past years, from 3.0 in 2007 to 4.1 in 2012. This antenatal increases in the municipality can be attributed to the coming into being of the free maternal healthcare policy. Hence, the policy has directly affected antenatal attendance.

Secondly, the research aimed at establishing the effect of the policy on the quality of care in the health facilities. Skilled care needs to be scaled up which would mean better usage of the human power that is available. Therefore, even though the policy has had an effect on quality of care, it has not been remarkable. Meaning more work needs to be done. Lastly, research aimed at establishing the prospects and challenges of the policy. Even though the policy has lots of challenges, it can be concluded that the policy should be maintained and strengthened as well as introduce other measures to reduce maternal mortality. 


\section{REFERENCES}

AbouZahr C., (2001), Cautious champions: International agency efforts to get safe motherhood onto the agenda. Studies in Health Services Organisation and Policy, 17, 387-414.

Alvarez, Jose, Luis et al (2009), Factors associated with maternal mortality in Sub-Saharan Africa: an ecological study. Research article [http://www.biomedcentral.com] Asante, D. F., and Aikins, D. M., (2007), Does the NHIS cover the poor? Pro-Poor research, University of Ghana, Legon, Accra.

Borghi, J., et al (2007), Mobilising financial resources for maternal health. The Lancet Maternal Survival Series steering group

GNA, (2010), "Ghana can achieve MDGs Four and Five - Dr Sory" Thursday, October 21st, 2010 | Posted by VibeGhana

Ghana Statistical Service (2008), Ghana Living Standards Survey Report Of The Fifth Round (GLSS 5)

Ghana Health Services (2006), Reproductive and Child Health Annual Programme of Work. Annual Programme of Work, Ghana Health Services, Ghana, Reproductive and Child Health.

Graham, W.J, Filippi V., Ronsmans, C. (1998), Demonstrating programme impact on maternal mortality. Health Policy Planning 1996; 11: 16-20. PubMed.

Immpact, PRB. (2007). Evaluating Removal of Delivery Fees in Ghana. Evaluation.

Kernaghan, K and Siegel, D., (1999), Public administration in Canada. Fourth Edition. Scarborough, Ontario: International Thompson Publishing

Lindblom, C., E., (2007), "The Science of "Muddling Through "Public Administration Review, Vol. 19, No. 2. (Spring, 1959), pp. 79-88.

Magadi, Monica A., Eliya M., Z., and Brockerhoff M., (2000). "The inequality of maternal health care in urban sub-Saharan Africa in the 1990s." Population Studies 57(3):347-366.

McDonagh, Marilyn, and Goodburn, Elizabeth (2000) Maternal Health and Health Sector Reform: Opportunities and Challenges. John Snow International, UK MICS. (2006). Monitoring the situation of Children, women and men. Multiple Indicator Cluster Survey, Accra.

Ministry of Health, (2007) National Health Policy: Creating Wealth through Health. Ministry of Health

Ministry of Health (2008) Independent Review Health Sector Programme Of Work 2007. Ministry of Health Ministry of Health, (2004), Ghana National Drug Policy. Ministry of Health

New Juaben Municipal Health Directorate (2007 -2012), Annual reports

Peter, P. and Budetti, M. D., (1998) "Health Insurance for Children- A Model for Incremental Health Reform?" Northwestern University Institute for Health Services Research and Policy Studies Evanston, IL 60208-4170

Patton, M.Q., (1990), Qualitative evaluation and research methods. SAGE Publications. Newbury Park London New Delhi Posasac, E.J. and Carey, R.G., (1992), Program Evaluation: Methods and Case studies. Fourth Edition. Englewood cliffs, New Jersey: Prentice Hall.

Ronsmans, C., and Graham, W. (2006), Maternal Mortality: who, when, where and why? (R. Horton, Ed.) The Lancet

Rosenberg, D., (1997), Trend Analysis and Interpretation, Division of Science, Education, and Analysis, Rockville, Maryland 20857

Senah, K. (2003), Maternal Mortality in Ghana: The Other Side. Institute of Africa Studies: Research Review

Thaddeus S. and Maine D., (1994), "Too far to walk: maternal mortality in context". Centre for Communication Programs, Johns Hopkins University, Baltimore, MD 21202-4024.

Witter, S., Arhinful, D. K., Kusi, A., and Zakariah-Akoto, S. (2007), The Experience of Ghana in Implementing a User Fee Exemption Policy to Provide Free Delivery Care. Reproductive Health Matters, 15 (30), 61-71.

World Health Organization (2008), Factsheet: Millennium Development Goal 5. World Health Organization

Yeboah, A. L., (2010) “Addressing Ghana's high maternal mortality rate” GNA, Monday, February 15, 2010. 


\section{APPENDIX}

\section{Definition of Terms}

TBA (Traditional Birth Attendant) - this refers to traditional, independent (of the health system), nonformally trained and community-based providers of care during pregnancy, childbirth and the postnatal period (USAID, 2008)

Millennium Development Goal (MDGs) - these are eight goals adopted in 2000 from the millennium summit to improved the development challenges and well-being of nations by 2015 (UNDP, 2006)

MMR (Maternal Mortality Rate) - this refers to the number of maternal deaths in given time period per 100,000 women of reproductive age, or woman-years of risk exposure, in same period (Lancet, 2006) Maternal death- this is the death of a woman while pregnant or within 42 days of termination of pregnancy, irrespective of the duration and site of the pregnancy, form any cause related to or aggravated by the pregnancy or its management, but not from accidental or incidental causes (Lancet, 2006).

NJMHD- refers to the New Juaben Municipal Health Directorate 